Gök, B. \& Baş, Ö. (2020). İlkokul 1. sınıf öğrencilerinin dik temel yazılarının okunaklılığı üzerine bir inceleme. Ana Dili Eğitimi Dergisi, 8(2), 572-585.

\begin{tabular}{c}
$\begin{array}{c}\text { Ana Dili Eğitimi Dergisi } \\
\text { Journal of Mother Tongue Education } \\
\text { www.anadiliegitimi.com }\end{array}$ \\
$\begin{array}{c}\text { Geliş/Received: } 28.02 .2020 \text { Kabul/Accepted: } 04.03 .2020 \\
\text { Araştırma Makalesi / Research Paper }\end{array}$ \\
\hline
\end{tabular}

\title{
İlkokul 1. Sınıf Öğrencilerinin Dik Temel Yazılarının Okunaklılığı Üzerine Bir İnceleme
}

\author{
Bilge GÖK** \\ Özlem $B A S^{* * *}$
}

\begin{abstract}
Öz
İlkokul 1. sınıf öğrencilerinin dik temel yazılarının okunaklılık bakımından incelenmesini amaçlayan bu araştırmada tarama modeli kullanılmıştır. Araştırmada öğrencilerin dik temel yazılarının okunaklıık düzeyi; okunaklılık ölçeğinden aldıkları puanların cinsiyete, sosyo-ekonomik düzeye, akademik başarı düzeyine ve kullanılan defter türüne göre farklılaşıp farklılaşmadığ belirlenmeye çalışılmıştır. Araştırmada öğrencilerin dik temel yazılarını okunakılıı açısından incelemek amacıyla "Çok Boyutlu Okunaklılık Ölçeği” dik yazıya uyarlanarak kullanılmıştır. Araştırmanın çalışma grubunu Ankara il merkezinde bulunan bir devlet okulunun 1. sınıfında okuyan 136 öğrenci oluşturmaktadır. Araştırmanın sonucunda ilkokul 1. sınıf öğrencilerinin dik temel yazılarının biçim boyutu dışında diğer tüm boyutlarda ve toplam puan açısından orta düzeyde okunaklı olduğu görülmüştür. Bununla birlikte öğrencilerin ölçekten aldıkları puanların cinsiyete göre boşluk, ebat, biçim alt boyutlarında ve toplam puan açısından kız öğrenciler lehine, başarı düzeyine göre ise tüm alt boyutlarda ve toplam puanda başarılı öğrenciler lehine anlamlı farklılık gösterdiği, sosyo-ekonomik düzeye ve kullanılan defter türüne göre anlamlı farklılık göstermediği görülmüştür.
\end{abstract}

Anahtar Kelimeler: Dik temel yazı, okunaklılık, ilkokul.

\section{Investigating the Legibility of Primary School $1^{\text {st }}$ Grade Students' Manuscript Writing Abstract}

This study aims to analyse the first graders' manuscript writing in terms of legibility. It was designed upon survey model. Within the scope of the study, it was questioned whether students' scores in the legibility of manuscript writing differed significantly in terms of gender, socioeconomic status, academic achievement and notebook types they use for handwriting. "Multi-Dimensional Legibility Scale" was adapted and used to analyse participants' writing. Participants were composed of 136 primary school students who were the first graders in a state school located in Ankara city centre. Findings of the study showed that the first graders' handwriting had medium level of legibility in terms of all factors except the factor of "form" and in terms of total scores. Additionally, it was also found that the scores students received from the scale differed significantly in sub-factors of space, size, and form according to gender in favour of girls. Additionally, they differed in all sub-factors and in total scores according to students' academic achievement levels in favour of students who were successful. Finally, they did not differ significantly according to socio-economic status and the type of notebooks they used for writing.

Keywords: Manuscript writing, legibility, primary school.

\footnotetext{
***oç. Dr., Hacettepe Üniversitesi, Eğitim Fakültesi, Temel Eğitim Bölümü, Ankara, bilgeb@hacettepe.edu.tr, ORCID: 0000-0002-1548-164X

**** Doç. Dr., Hacettepe Üniversitesi, Eğitim Fakültesi, Temel Eğitim Bölümü, Ankara, ozlembas@hacettepe.edu.tr, ORCID: 0000-0002-0716-103X
} 


\section{Giriş}

Çocuklarda okunaklı el yazısı yazma becerisi geliştirme hem bir çocuğun yaşam boyu kullanacağı bir beceri olması açısından hem de bir ülkenin yazma kültürü açısından büyük önem teşkil eder. Okuma yazma becerilerinin öğretildiği ilkokul 1. sınıf ise en kritik adımların atıldığı ilk aşamadır. Bu aşamada çocuk harf sembollerini nasıl üreteceğini öğrenir ve yazmada otomatikleşmeye başlar. Bu nedenle öğretmenler acele etmemeli okunaklı bir yazma becerisi kazandırma yolunda özellikle ilk okuma yazmaya hazırlık aşamasından itibaren okunaklı yazmanın önemini bir bilinç olarak öğrencilerde geliştirmelidir.

Okullarda bilgisayarların yaygınlaşmasına rağmen, okunaklı el yazısı yazmak değerini korumakta ve yazmayla ilgili görevlerde önemli bir yaşam becerisi olarak gereklilik teşkil etmektedir (Feder ve Majnemer, 2003, 66). El yazısı, okul çağı çocuğu için öğreneceği en bireysel beceridir; hayatla iletişim kurma ve birey olarak tanınmanın anlamı, karmaşık becerilere dayanan birçok unsurun bir araya gelmesiyle ortaya çıkan bir üründür(Duncan, 1982,1).

Eagon $(1959,4)$ dik temel yazıyı terim olarak "Hem büyük harfler hem de küçük harfler için Roma formlarını yakından takip ederek daire veya kısmı düz çizgilere dayanan harflerin yazı tipi" olarak tanımlamıştır. Güneş $(2017,4)$ "Dik temel yazı, her harfin düz ve sade çizgilerle 90 derece dik yazıldığı bir yazıdır." diye tanımlar ve dik temel yazıda ilkokula yeni başlayan öğrencilerin fazla güçlükle karşılaşmamaları ve yazıyı iyi tanımaları için basitleştirilmiş şekiller kullanıldığını vurgular.

Dik temel yazıda harflerin yazım özellikleri şöyledir (Lessard, 1977, akt. Güneş, 2017, s.4 ):

"1. Dikey yazılanlar: I, i, I, j;

2. Yuvarlak ve sola eğik yazılanlar: o, ö, c, ç, e;

3. Yuvarlak başlayıp dik bitenler: $a, d, g$, $\breve{g}$;

4. Dik başlayıp sağa eğik bitenler: $n, m, h, b, p, r$;

5. Aşağıya doğru eğik başlayıp dik bitenler: $u, \ddot{u}, y$;

6. Karışık yazılanlar: $v, k, z$;

7. íki çizgiyle yazılanlar: $t, f$;

8. Sola eğik başlayıp sağa eğik bitenler: $s$, ş."

Blair (1957) dik temel yazının daha okunaklı olduğunu, çocukların öğrenmesi açısından daha kolay ve ritmik olduğunu, el kasılmalarını azalttığını ve günlük hayatta kullanımının yaygın olduğunu belirtmektedir. Bu doğrultuda öğretmenlerin bitişik eğik yazı kullanıldığı dönemlerde tahtaya yazarken dik temel yazı kullanımını bırakmamış oldukları bulgusu dik yazının günlük hayattaki kullanımı açısından önemli bir bulgudur (Yıldız, Yıldırım, Ateş, 2009, 83).

2018 Türkçe Öğretim Programında öğretmenin tercihine bırakılan dik temel yazı öğretimi $(2018,10) 2019$ Türkçe Öğretim Programında $(2019,10)$ "ilk okuma yazma öğretimi tırnaksız dik temel harflerle gerçekleştirilir." ifadesiyle tamamen uygulamaya geçmiştir. Graham ve Miller $(1980,3)$ dik temel yazının ilk olarak Amerika Birleşik Devletleri'nde 1920'li yıllarda tanıtıldığını ve ilerleyen yirmi otuz yılda aşama aşama kabul gördüğünü belirtirken Amerika Birleşik Devletleri'nde dik temel yazı 1 ve 2. sınıfta öğretilmekte, 3. sınıfta bitişik eğik yazıya geçilmektedir, der. Her iki yazı tipinin bir arada öğretimi yaygınken, bazı uzmanlara göre bir tek yazı tipi kullanmak gereklidir. Bara ve Morin (2013)'ün " 1 . sınıfta öğrenilen el yazısı modeli, 4 ve 5. sınıflarda yazının niteliğine ve hızına etki ediyor mu?" isimli Fransız ve Kanadalı öğrencilerin karşılaştırmasını yaptığı araştırmada sonuçlar; ülke, sınıf seviyesi, seçilen el yazısı modeli, el yazısı öğretiminin yapılandırılmasının önemli olduğunu ortaya koymaktadır. Araştırma sonuçlarına göre dik temel yazı yazan Kanadalı öğrenciler, bitişik eğik yazı yazan Fransız öğrencilerden daha hızı yazmaktadır ancak yazıları daha okunaksızdır.

Temelde el yazısı öğretiminin yapılandırılması ilkokullarda öğretmenin sorumluluğundadır (Graham ve Miller, 1980, akt. Asher, 2006). Öğretmenler motor problemler ve görsel algı problemlerinden kaynaklı olarak öğrencilerin el yazısında zorluklar yaşadıklarını dile getirmektedirler (Graham, Harris, Mason, Fink-Chorzempa, Moran ve Saddler, 2008, 64). El yazısı performansını etkileyen birçok unsur vardır; bunlar ince motor kasların kontrolü, görsel motorsal uyum, el tercihi, oranlama, görsel algı, dikkat, parmaklarda duygusal farkındalık gibi bileşenlerdir (Feder ve Mejnemer, 2007, 312). Bu nedenlerden dolayı çocukların el yazısı okunaklıık açısından etkilenmektedir. Yazı 
öğretiminde en önemli unsur okunaklııktır. Yazıda okunaklılık gözün biçimsel nedenlerden kaynaklı olarak yazıya takılmamasıdır (Atasoy, 2018, 220). Türkiye'de okunaklılık üzerine yapılmış araştırmalar incelendiğinde eğim, boşluk, ebat, biçim, satır takibi unsurlarının analiz edildiği görülmektedir (Yıldız, Yıldırım ve Ateş, 2009, Kuru, 2014, Yıldız, 2013, Kodan, 2016), Kuşdemir, Katrancı ve Arslan (2018b) ise ilkokul öğrencilerinin yazı okunaklılığıyla ilgili sınıf öğretmenleri ve velilerin görüşleri belirlemeye çalışmışlardır. Araştırma sonucunda, sınıf öğretmenlerinin görüşlerine göre öğrencilerin yazılarının okunaksız olması öğrenciden, kullanılan yazı türünden, öğretmenden ve aileden kaynaklanmaktadır. Araştırmada velilerden elde edilen verilere göre velilerin öğenim düzeyi arttıkça çocukların yazı okunaklılı̆ı hakkındaki görüşlerinin de olumlu yönde değiştiği belirlenmiştir. Ayrıca çocuğu herhangi bir sebeple okul veya öğretmen değiştiren velilerin büyük bir kısmı çocuğunun yazısını yeterince okunaklı bulmamaktadır.

Türkiye'deki araştırmalar incelendiğinde son on dört yıldır bitişik eğik yazı uygulamaları programda olduğu için bitişik eğik yazı öğretimini değerlendiren çalışmalar yapıımıştır (Duran, 2009, Yıldız, Yıldırım ve Ateş, 2009, Duran ve Akyol, 2010, Duran, 2011, Erdoğan, 2012, Yıldız, 2013, Kuru, 2014, Kodan, 2016, Kuşdemir, Katrancı ve Arslan, 2018a). Yurtdışında yapılmış araştırmalar incelendiğinde dik yazı öğretimine ilişkin çalışmaların çok eski dönemlerde kaldığı alan yazın açısından dikkati çekerken, bu araştırmaların sonuçları birinci sınıf öğretmenlerinin başlangıç seviyesindeki öğrenciler için dik temel yazının öğrenim kolaylığı olduğunu düşünmesi, okuma öğretimi açısından daha uygun bulması, dik temel yazıda okunaklı yazan öğrencilerin bitişik eğik yazıda da okunaklı yazdığı bulguları yer almaktadır (Preston, 1941; Blair, 1957; Thomas, 1966; McIntyre, 1974;Duncan, 1982).

Dik temel yazı öğretiminin Türkiye'de yeniden ilkokuma yazma öğretim programlarında yer almasından sonra öğrenci yazılarının incelendiği çalışmalar aslında okunaklılıkla ilgili yıllardır süregelen tartışmalara rağmen dik temel yazının da okunaklılıkta büyük bir değişim yaratmadığını ortaya koymaktadır (Babayiğit, 2018; Babayiğit, Karabay, Metin ve Halıcı, 2018; Ulu, 2019). Nitekim dik temel yazı öğretimine yönelik yapılan araştırmalar öğretmenlerin ve öğrencilerin bu yazı stilini kullanma tercihlerinin temelinde okunaklı olduğu düşüncesine yer verir ve ortaokula geçişte kullanım sıklığı dikkati çeker (Bulut, Kuşdemir ve Şahin, 2016; Arcagök, Kobak, Demir ve Çavuş, 2017; Çakır, Aslantaş Arslan ve Doğan, 2018; Yıldız, 2019). Bu bağlamda bu araştırma dik temel yazıda okunaklıı̆ı incelemesi ve okunaklılığı etkileyen cinsiyet, başarı düzeyi ve sosyo-ekonomik düzey gibi değişkenleri ele alması bakımından önem teşkil etmektedir.

Araştırmada ilkokul 1.sınıf öğrencilerinin dik temel yazılarının okunaklııı boyutunun incelenmesi amaçlanmış ve bu kapsamda araştırmada aşağıdaki sorulara yanıt aranmıştır:

1. illkokul 1.sınıf öğrencilerinin dik temel yazılarının okunaklılık düzeyi nedir?

2. İlkokul 1. sınıf öğrencilerinin yazı okunaklılığı alt boyutlarından aldıkları puanlar;

a) cinsiyete göre farklılık göstermekte midir?

b) sosyo-ekonomik düzeye göre farklılık göstermekte midir?

c) akademik başarıya göre farklıık göstermekte midir?

d) kullandıkları defter türüne göre farklılık göstermekte midir?

\section{Araştırma Deseni}

\section{Yöntem}

Illkokul 1. sınıf öğrencilerinin dik temel yazılarının okunaklılık bakımından incelenmesini amaçlayan bu araştırma, tarama modeli tipinde nicel bir araştırmadır. Tarama araştırmaları, bir konuya ya da olaya ilişkin katılımcıların görüşlerinin ya da ilgi, beceri, yetenek, tutum vb. özelliklerinin belirlendiği genellikle diğer araştırmalara göre görece daha büyük örneklemler üzerinde yapılan araştırmalardır. Bu araştırmaların asıl amacı, bir topluluğun özelliklerini tanımlamak ve bu özelliklerin grup içinde nasıl dağıldığını ortaya çıkarmaktır (Frankel, Wallen \& Hyun, 2012).

\section{Çalışma Grubu}

Araştırmanın çalışma grubunu Ankara il merkezinde bulunan bir devlet okulunun 1. sınıfında okuyan 136 ilkokul öğrencisi oluşturmaktadır. Çalışma grubunun belirlenmesinde, kolay ulaşılabilir 
durum örneklemesi tercih edilmiştir. Çünkü bu yöntemde araştırmacı, yakın olan ve erişilmesi kolay olan bir durumu seçer (Creswell \& Clark, 2018). Öğrenciler uygun ve gönüllü oldukları için bu çalışmaya dâhil edilmiş fakat araştırmanın yapıldığı dönemde hala okuma-yazmaya geçememiş öğrenciler çalışmaya dâhil edilmemiştir. Araştırma, 2019-2020 eğitim-öğretim yılı güz yarıyılında 1. sınıf Türkçe dersi kapsamında gerçekleştirilmiştir. Bu öğrencilerin 62'si (45.6) kız, 74'ü (54.4) erkek olup, 69'u (\%50.7) alt sosyo-ekonomik düzeyden, 67'si (\%49.3) ise üst sosyo-ekonomik düzeyden gelmektedir. Öğrencilerin sosyo-ekonomik düzeyleri belirlenirken TÜik tarafından açıklanan aylık ortalama gelir dikkate alınmıştır. Bu doğrultuda, aylık ortalama geliri belirlenen değerin altında olanların alt sosyo-ekonomik düzeyde, üstünde olanların ise üst sosyo-ekonomik düzeyde olduğu kabul edilmiştir. Öğrencilerin yarısı (\%50) akademik başarısı yüksek, diğer yarısı (\%50) ise akademik başarısı düşük öğrencilerden oluşmaktadır. Öğrencilerin akademik başarısı belirlenirken, öğretmen görüşleri doğrultusunda Türkçe dersi başarısı dikkate alınmıştır. Öğrencilerin 86'sı (\%63.2) klasik defter kullanırken, 50’si (\%36.8) ise üç satır aralıklı çizgili defter kullanmaktadır.

\section{Veri Toplama Araçları}

Araştırmada ilkokul 1.sınıf öğrencilerinin dik temel yazılarını okunaklııı açısından incelemek amacıyla Yıldız ve Ateş $(2007,2010)$ tarafından geliştirilen "Çok Boyutlu Okunaklılık Ölçeği" dik yazıya uyarlanarak kullanılmış ve araştırmada kullanılan ölçme aracı Ek 1'de verilmiştir. Bu kapsamda öğrencilerin dik temel yazıyı kullanarak öğretmeni tarafından daha önce defterlerine yazdırılmış yazılar iki farklı puanlayıcı tarafından puanlanmış ve iki farklı puanlayııının yaptıkları değerlendirmeler arasındaki uyuşmayı tespit etmek ve güvenilir olup olmadığını belirlemek için Cohen'in Kappa katsayısı hesaplanmıştır. Hesaplanan uyuşma katsayısı $K=0.80(p=0.00<0.01)$ olarak bulunmuştur. Önemli düzeyde bir uyumun olması için Kappa istatistiğinin 0.60 'dan düşük olmaması ve $0.70^{\prime}$ den büyük olması gerekmektedir. Kappa katsayısı, 0.40 ile 0.59 arasında ise makul bir uyuşma; 0.60-0.79 arasında ise önemli bir uyuşma ve 0.80 'den büyükse mükemmel bir uyuşma olduğunu gösterir (Landis ve Koch, 1977). Buradan hareketle araştırmadan elde edilen sonuç, puanlayıcılar arasında mükemmel bir uyuşma olduğunu göstermektedir. Elde edilen bu sonucun, güvenirliğe ilişkin kanıt sağladığı ifade edilebilir.

Bununla birlikte "Çok Boyutlu Okunaklılık Ölçeği" , "tamamen yeterli (3)", "orta düzeyde yeterli (2)" ve "hiç yeterli değil (1)" olmak üzere üç kategoriden oluşmaktadır. Analitik değerlendirme yaklaşıma göre hazırlanan dereceli puanlama anahtarında okunaklılık kriterleri; eğim, boşluk, ebat, biçim ve satır takibi olarak belirlenmiştir. Bu doğrultuda araştırmada öğrencilerin dik temel yazıları her bir alt boyut için ayrı ayrı ele alınmıştır. Ayrıca öğrencinin cinsiyeti, akademik başarısı, sosyoekonomik düzeyi gibi kişisel bilgilerin yer aldığı bir form oluşturulmuştur.

\section{Verilerin Analizi}

Araştırmaya katılan ilkokul 1.sınıf öğrencilerinin dik temel yazılarını değerlendirmek amacıyla kullanılan "Çok Boyutlu Okunaklılık Ölçeği" nin alt boyutlarından elde edilen verilerin parametrik test varsayımlarını karşılayıp karşılamadığı istatistiki açıdan test edilmiştir. Gruplardan elde edilen verilerin normal dağılımı "çarpıklık, basıklık katsayıları, çarpıklık ve basıklık katsayılarının kendi standart hatasına bölünmesiyle elde edilen çarpıklık ve basıklık indeksleri", "Kolmogorov-Smirnov testi" ve grafikler (box plot, histogram ve çizgi grafikleri) yoluyla incelenmiştir. Varyansların homojenliği ise "Levene's Test of Equality of Error Variances (Levene Hata Varyansları Eşitliği Testi)" ile değerlendirilmiştir. Kolmogorov-Smirnov testi ve Levene testi sonucunda $p$ değerleri 0.05 'den küçük ve çarpıklık-basıklık katsayıları ve indeksleri istenilen aralıkta olmadığı, grafikler de normalliğe ilişkin gösterimler sunmadığı için verilerin dağılımının normal ve varyanslarının homojen olmadığı söylenebilir. Tüm bu sonuçlar dikkate alındığında verilerin parametrik test koşullarını karşılamadığı görüldüğü için parametrik olmayan istatistikler kullanılmıştır. Verilerin analizinde parametrik olmayan istatistikler içinden, iki ilişkisiz örneklemden elde edilen puanların birbirlerinden anlamlı farklılık gösterip göstermediğini test etmek için "Mann-Whitney $U$ testi” kullanılmıştır. Bununla birlikte araştırmada, değişkenler arasındaki ilişkinin gücünü kararlaştırmada etki büyüklükleri hesaplanmış ve 
0.10, 0.30 ve 0.50 düzeyindeki eta-kare değerleri aynı sırayla küçük, orta ve büyük (geniş) etki olarak yorumlanmıştır (Cohen, 1992, 1988; Akt. Field, 2005). Verilerin analizi SPSS 23.0 paket programında yapılmıştır.

\section{Bulgular}

Bu bölümde, araştırma bulgularına ve bu bulgularla ilgili değerlendirmelere yer verilmiştir.

Araştırmada ilkokul 1. sınıf öğrencilerinin yazı okunaklılığı alt boyutlarından aldıkları puanlara ilişkin betimsel istatistikler Tablo 1'de verilmiştir.

Tablo 1.

ilkokul 1. Sınıf Öğrencilerinin Yazı Okunakııı̆̆ı Alt Boyutlarından Aldıkları Puanlara ilişskin Betimsel istatistikler (N:136)

\begin{tabular}{lllll}
\hline $\begin{array}{l}\text { Okunaklı̆ı̆ı Değerlendirme } \\
\text { Dereceli Puanlama Anahtarı }\end{array}$ & $\begin{array}{l}\text { En düşük puan } \\
\text { (Min) }\end{array}$ & $\begin{array}{l}\text { En yüksek puan } \\
\text { (Max) }\end{array}$ & $\left.\begin{array}{l}\text { Aritmetik } \\
\text { ortalama }\end{array} \overline{\bar{X}}\right)$ & Standart sapma (Ss) \\
\hline Eğim & 1.00 & 3.00 & 2.17 & 7.13 \\
Boşluk & 1.00 & 3.00 & 1.83 & 7.96 \\
Ebat & 1.00 & 3.00 & 1.87 & 0.79 \\
Biçim & 1.00 & 3.00 & 1.64 & 0.67 \\
Satır takibi & 1.00 & 3.00 & 2.25 & 0.80 \\
\hline Toplam & 5.00 & 15.00 & 9.76 & 3.11 \\
\hline
\end{tabular}

Tablo 1'de yazı okunaklılığı eğim, boşluk, ebat, biçim ve satır takibi boyutlarından öğrencilerin aldıkları puan ortalamaları sırasıyla görülmektedir. "Çok Boyutlu Okunaklııı Ölçeği”" ne göre her bir boyut için 1-1.66 arası hiç yeterli değil, 1.67-2.32 arası orta düzeyde yeterli, 2.33 ile 3 arası tamamen yeterli olarak nitelendirilirken, toplam puan açısından 5-8.3 arası olan öğrencilerin yazıları okunaklı değil, 8.4-11.7 olan öğrencilerin yazıları orta düzeyde okunaklı, toplam puanı 11.8-15 olan öğrencilerin yazıları ise, okunaklı olarak değerlendirilmiştir. Bu kriterler dikkate alınarak bulgular incelendiğinde, biçim boyutu dışında diğer tüm boyutlarda ve toplam puan açısından öğrencilerin yazılarının orta düzeyde okunaklı olduğu görülürken, en yüksek performansın satır takibi ve eğim boyutlarında en düşük performansın ise biçim boyutunda sergilendiği görülmüştür.

Araştırmada ilkokul 1.sınıf öğrencilerinin yazı okunaklılı̆ı alt boyutlarından ve okunabilirlik toplam puanından elde edilen verilerin cinsiyete göre anlamlı farklılık gösterip göstermediğine "Mann-Whitney U testiyle" bakılmış ve sonuçlar Tablo 2' de verilmiştir.

Tablo 2.

ilkokul 1. Sını Öğrencilerinin Yazı Okunaklıı̆ı Alt boyutları ve Toplam Okunabilirlik Puanının Cinsiyete Göre Mann Whitney U Testi Sonuçları

\begin{tabular}{llllllll}
\hline Alt boyutlar & Cinsiyet & $n$ & Sıra ortalaması & $\begin{array}{l}\text { Sıra } \\
\text { toplamı }\end{array}$ & U & $p$ & $\begin{array}{l}r \text { (etki } \\
\text { büyüklüğü) }\end{array}$ \\
\hline Eğim & Kız & 62 & 71.58 & 4438.00 & 2103.00 & 0.38 & \\
& Erkek & 74 & 65.92 & 4878.00 & & & 0.23 \\
Boşluk & Kız & 62 & 79.51 & 4929.50 & 1612.00 & $0.00^{*}$ & \\
& Erkek & 74 & 59.28 & 4386.50 & & & 0.16 \\
Ebat & Kız & 62 & 77.31 & 4793.00 & 1748.00 & $0.01^{*}$ & 0.07 \\
& Erkek & 74 & 61.12 & 4523.00 & & & \\
Biçim & Kız & 62 & 75.56 & 4685.00 & 1856.00 & $0.04^{*}$ & 0.17 \\
& Erkek & 74 & 62.58 & 4631.00 & & & \\
Satır takibi & Kız & 62 & 73.29 & 4544.00 & 1997.00 & 0.17 \\
& Erkek & 74 & 64.49 & 4772.00 & & & \\
\hline Toplam & Kız & 62 & 76.29 & 4730.00 & 1811.00 & $0.03^{*}$ & 0.18 \\
& Erkek & 74 & 61.97 & 4586.00 & & &
\end{tabular}


Tablo 2 incelendiğinde, ilkokul 1. sınıf öğrencilerinin yazı okunaklılı̆ı boşluk (U=1612.00; $p<0.05)$, ebat $(U=1748.00 ; p<0,05)$, biçim $(U=1856 ; p<0,05)$ alt boyutlarından ve ölçeğin toplamından aldıkları puanların cinsiyete göre anlamlı farklılık gösterdiği görülürken; eğim ( $U=2103.00 ; p>0.05)$ ve satır takibi (U=1997.00; $p>0.05)$ alt boyutlarında cinsiyete göre anlamlı farklılık olmadığı görülmektedir. Sıra ortalamaları dikkate alındığında, boşluk, ebat, biçim alt boyutlarında ve okunabilirlik toplam puanı açısından kız öğrencilerin puan ortalamalarının erkek öğrencilerden daha yüksek olduğu anlaşılmaktadır. Bununla birlikte etki büyüklükleri incelendiğinde sırasıyla eğim, boşluk, ebat alt boyutları ve toplam puan için bu değer $r=0.23, r=0.16, r=0.07$ ve $r=0.18$ olarak bulunmuştur. Elde edilen bu değer, kız ve erkek öğrencilerin yukarıda sözü edilen alt boyutlarda ve toplam puanlarında çok büyük bir fark olmadığını göstermektedir.

Araştırmada ilkokul 1. sınıf öğrencilerinin yazı okunaklılı̆ı alt boyutlarından ve okunaklıık toplam puanından elde edilen verilerin sosyo-ekonomik düzeye göre anlamlı farklılık gösterip göstermediğine "Mann-Whitney U testiyle" bakılmış ve sonuçlar Tablo 3'de verilmiştir.

Tablo 3.

ilkokul 1. Sınıf Öğrencilerinin Okunaklılığı Değerlendirme Dereceli Puanlama Anahtarının Alt Boyutlarının Sosyo-Ekonomik Düzeye Göre Mann Whitney U Testi Sonuçları

\begin{tabular}{lllllll}
\hline Alt testler & $\begin{array}{l}\text { Sosyo- } \\
\text { Ekonomik } \\
\text { Durum }\end{array}$ & $n$ & Sıra ortalaması & $\begin{array}{l}\text { Sıra } \\
\text { toplamı }\end{array}$ & $U$ & $p$ \\
\hline Eğim & Alt & 69 & 62.30 & 4299.00 & 1884.00 & 0.05 \\
& Üst & 67 & 74.88 & 5017.00 & & \\
Boşluk & Alt & 69 & 64.46 & 4447.50 & 2032.00 & 0.21 \\
& Üst & 67 & 72.66 & 4868.50 & & \\
Ebat & Alt & 69 & 62.28 & 4297.00 & 1882.00 & 0.05 \\
& Üst & 67 & 74.91 & 5019.00 & & \\
Biçim & Alt & 69 & 62.41 & 4306.50 & 1892.00 & 0.05 \\
& Üst & 67 & 74.77 & 5009.50 & & \\
Satır takibi & Alt & 69 & 64.86 & 4475.50 & 2060.50 & 0.25 \\
& Üst & 67 & 72.25 & 4840.50 & & \\
\hline Toplam & Alt & 69 & 61.91 & 4271.50 & 1856.00 & 0.05 \\
& Üst & 67 & 75.29 & 5044.50 & & \\
\hline
\end{tabular}

Tablo 3 incelendiğinde, 1. sınıf ilkokul öğrencilerinin "Çok Boyutlu Okunaklılık Ölçeği” nin eğim ( $U=1884.00 ; p>0.05)$, boşluk ( $U=2032.00 ; p>0.05)$, ebat $(U=1882.00 ; p>0.05)$, biçim ( $U=1892.00$; $p>0.05)$, satır takibi $(U=2060.50 ; p>0.05)$, alt boyutlarından ve ölçeğin tamamından ( $U=1856.00$; $p>0.05$ ) aldıkları puanların sosyo-ekonomik düzeye göre anlamlı farklılık göstermediği görülmektedir. Sosyo-ekonomik düzey açısından ortaya çıkan fark anlamlı olmamakla birlikte, sıra ortalamaları dikkate alındığında, tüm alt boyutlarda ve toplam puan açısından üst sosyo-ekonomik düzeydeki öğrencilerin puan ortalamalarının alt sosyo-ekonomik düzeydeki öğrencilerden daha yüksek olduğu anlaşılmaktadır.

Araştırmada ilkokul öğrencilerinin çok boyutlu okunaklılı̆ı değerlendirme dereceli puanlama anahtarının alt boyutlarından elde edilen verilerin başarı düzeyine göre anlamlı farklılık gösterip göstermediğine "Mann-Whitney U testiyle" bakılmış ve sonuçlar Tablo 4'te verilmiştir 
Tablo 4.

Ilköğretim 1. Sınıf Öğrencilerinin Yazı Okunaklıı̆ı Alt Boyutlarının ve Okunabilirlik Toplam Puanının Akademik Başarı Düzeyine Göre Mann Whitney U Testi Sonuçları

\begin{tabular}{|c|c|c|c|c|c|c|c|}
\hline Alt testler & $\begin{array}{l}\text { Akademik } \\
\text { Başarı } \\
\text { Düzeyi }\end{array}$ & $n$ & $\begin{array}{l}\text { Sira } \\
\text { ortalaması }\end{array}$ & $\begin{array}{l}\text { Sira } \\
\text { toplamı }\end{array}$ & $U$ & $p$ & $\begin{array}{c}r \\
\text { (etki } \\
\text { büyüklüğü) }\end{array}$ \\
\hline \multirow[t]{2}{*}{ Eğim } & Yüksek & 68 & 85.32 & 5801.50 & 1168.00 & $0.00^{*}$ & 0.45 \\
\hline & Düşük & 68 & 51.68 & 3514.50 & & & \\
\hline \multirow[t]{2}{*}{ Boşluk } & Yüksek & 68 & 91.72 & 6237.00 & 733.00 & $0.00^{*}$ & 0.61 \\
\hline & Düşük & 68 & 45.28 & 3079.00 & & & \\
\hline \multirow[t]{2}{*}{ Ebat } & Yüksek & 68 & 89.17 & 6063.50 & 906.50 & $0.00^{*}$ & 0.54 \\
\hline & Düşük & 68 & 47.83 & 3252.50 & & & \\
\hline \multirow[t]{2}{*}{ Biçim } & Yüksek & 68 & 92.57 & 6294.50 & 675.50 & $0.00^{*}$ & 0.65 \\
\hline & Düşük & 68 & 44.43 & 3021.50 & & & \\
\hline \multirow[t]{2}{*}{ Satır takibi } & Yüksek & 68 & 92.82 & 6312.00 & 658.00 & $0.00^{*}$ & 0.65 \\
\hline & Düşük & 68 & 44.18 & 3004.00 & & & \\
\hline \multirow[t]{2}{*}{ Toplam } & Yüksek & 68 & 95.04 & 6462.50 & 507.50 & $0.00^{*}$ & 0.67 \\
\hline & Düşük & 68 & 41.96 & 2853.50 & & & \\
\hline
\end{tabular}

${ }^{*} 0.05$

Tablo 4'e göre, ilkokul öğrencilerinin yazı okunaklılı̆ı eğim ( $U=1168.00 ; p<0.025)$, boşluk $(U=733.00 ; p<0.05)$, ebat $(U=906.50 ; p<0.05)$, biçim $(U=675.50 ; p<0.05)$, satır takibi $(U=658.00$; $p<0.05)$ alt boyutlarından ve ölçeğin toplamından $(U=507.50 ; p<0.05)$ aldıkları puanların akademik başarı düzeyine göre anlamlı farklılık gösterdiği görülmektedir. Sıra ortalamaları dikkate alındığında, tüm alt boyutlarda ve toplam puan açısından başarılı öğrencilerin puan ortalamalarının başarısız öğrencilerden daha yüksek olduğu anlaşılmaktadır. Bununla birlikte etki büyüklükleri incelendiğinde sırasıyla eğim, boşluk, ebat alt boyutları ve toplam puan için bu değer $r=0.45, r=0.61, r=0.54, r=0.65$, $r=0.65$ ve $r=0.67$ olarak bulunmuştur. Elde edilen bu değer, başarılı ve başarısız öğrencilerin yukarıda sözü edilen alt boyutlarda ve toplam puanlarında oldukça büyük bir fark olduğunu göstermektedir.

Araştırmada ilkokul öğrencilerinin yazı okunaklılığı alt boyutlarından ve okunabilirlik toplam puanından elde edilen verilerin kullanılan defter türüne göre anlamlı farklılık gösterip göstermediğine "Mann-Whitney U testiyle" bakılmış ve sonuçlar Tablo 5'da verilmiştir.

Tablo 5.

Ilköğretim 1. Sınıf Öğrencilerinin Yazı Okunaklılığı Alt Boyutlarının ve Okunabilirlik Toplam Puanının Defter Türüne Göre Mann Whitney U Testi Sonuçları

\begin{tabular}{|c|c|c|c|c|c|c|}
\hline Alt testler & Defter Türü & $n$ & Sıra ortalaması & Sıra toplamı & $U$ & $p$ \\
\hline \multirow[t]{2}{*}{ Eğim } & Klasik & 86 & 65.71 & 5651.00 & 1910.00 & 0.26 \\
\hline & Üç satır aralıklı & 50 & 73.30 & 3665.00 & & \\
\hline \multirow[t]{2}{*}{ Boşluk } & Klasik & 86 & 66.42 & 5712.00 & 1971.00 & 0.40 \\
\hline & Üç satır aralıklı & 50 & 72.08 & 3604.00 & & \\
\hline \multirow[t]{2}{*}{ Ebat } & Klasik & 86 & 63.54 & 5464.50 & 1724.00 & 0.05 \\
\hline & Üç satır aralıklı & 50 & 77.03 & 3851.50 & & \\
\hline \multirow[t]{2}{*}{ Biçim } & Klasik & 86 & 66.91 & 5754.50 & 2014.00 & 0.51 \\
\hline & Üç satır aralıklı & 50 & 71.23 & 3561.50 & & \\
\hline \multirow[t]{2}{*}{ Satır takibi } & Klasik & 86 & 68.34 & 5877.00 & 2136.00 & 0.95 \\
\hline & Üç satır aralıklı & 50 & 68.78 & 3439.00 & & \\
\hline \multirow[t]{2}{*}{ Toplam } & Klasik & 86 & 65.49 & 5632.50 & 1892.00 & 0.24 \\
\hline & Üç satır aralıklı & 50 & 73.67 & 3683.50 & & \\
\hline
\end{tabular}

Tablo 5'e göre, ilkokul öğrencilerinin yazı okunaklılığı eğim (U=1910.00; p>0.05), boşluk $(U=1971.00 ; p>0.05)$, ebat $(U=1724.00 ; p>0.05)$, biçim $(U=2014.00 ; p>0.05)$, satır takibi $(U=2136.00$; $p>0.05)$ alt boyutlarından ve ölçeğin toplamından $(U=1892.00 ; p>0.05)$ aldıkları puanların kullanılan 
defter türüne göre anlamlı farklılık göstermediği görülmektedir. Kullanılan defter türü açısından ortaya çıkan fark anlamlı olmamakla birlikte, sıra ortalamaları dikkate alındığında, tüm alt boyutlarda ve toplam puan açısından üç satır aralıkı çizgili defter kullanan öğrencilerin puan ortalamalarının klasik defter kullanan öğrencilerden daha yüksek olduğu anlaşılmaktadır

Araştırmadan elde edilen bulgular doğrultusunda öğrenci yazı örneklerine bakılacak olursa Resim 1'de; K27 kodlu Türkçe dersi akademik başarısı düşük erkek öğrencinin yazısında okunaklılık açısından eğim, boşluk, ebat, satır takibi ve özellikle biçim alt boyutlarında bir takım yetersizlikler görülmektedir. Öğrencinin yazısında eğim boyunda kısmen sola yatık yazdığı, boşlukları ayarlayamadığı, harflerin ebatlarının tutarlı olmadığı ve satır takibinde kaymalar olduğu tespit edilmiştir. Diğer bir göze çarpan sorun da harflerin biçimsel özelliklerinin okunaklı yazılmamış olmasıdır.

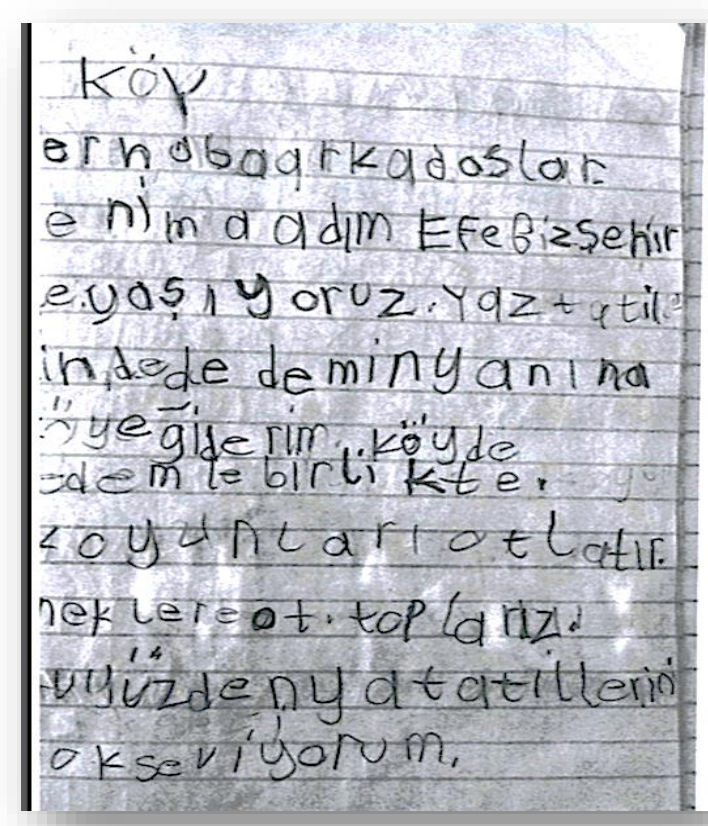

Şekil 1. Türkçe Dersi Akademik Başarısı Düşük Erkek Öğrenci Defteri Örneği [K

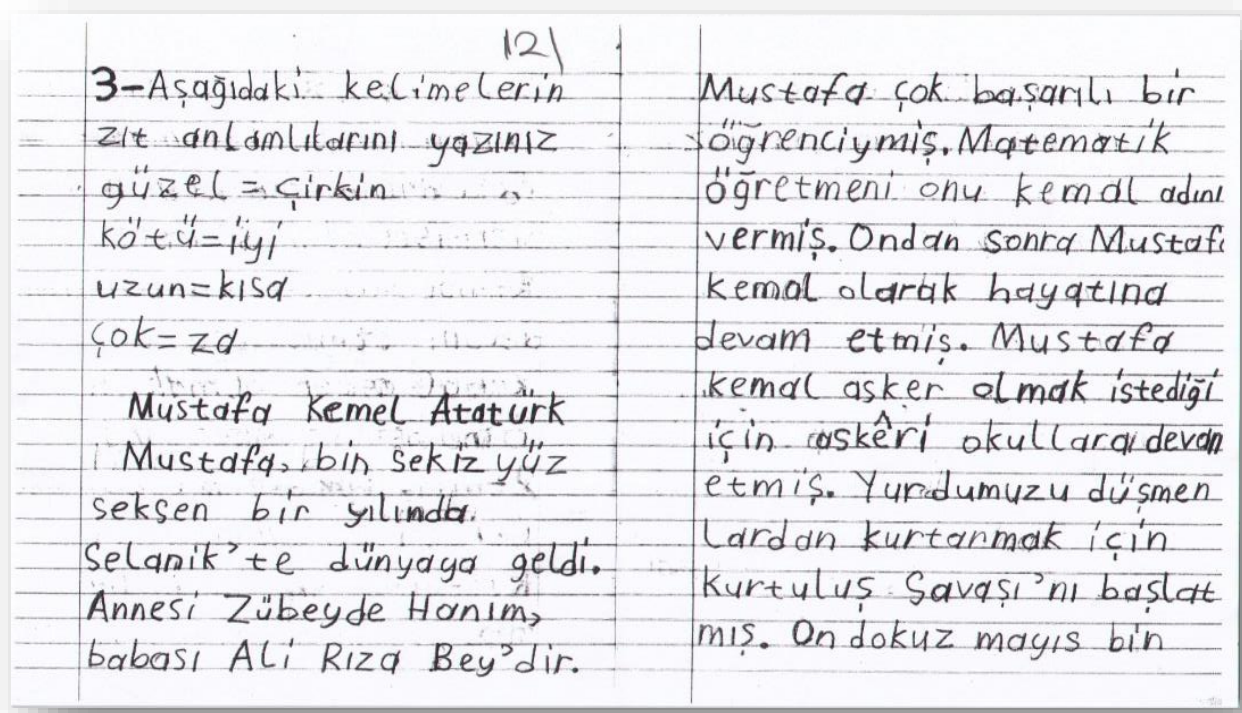

Şekil 2. Türkçe Dersi Akademik Başarısı Yüksek Kız Öğrenci Defteri Örneği [K121] 
K121 kodlu Türkçe dersi akademik başarısı yüksek kız öğrencinin yazısı incelendiğinde; eğim yüzde doksana yakın olmakla beraber, boşluklar oranlı bırakılmış, ebat hemen hemen uygun yazıımış, satır takibi düzenli yapılmış ve biçim bakımından okunaklı diyebileceğimiz bir yazı örneği ortaya çıkmıştır. Bu defterde dikkati çeken diğer bir bulgu da öğrencinin harflerin alt uzantılarını uygun ebatta çizememiş olmasıdır. Bu durum araştırmada defter kullanımıyla ilgili üç satır aralıklı standart yazı defterinin öğretmenler tarafından kullanılması gerektiğine dikkat çekmesi açısından önemlidir.

\section{Tartışma ve Sonuç}

İlkokul 1. sınıf öğrencilerinin dik temel yazılarının okunaklıı̆ı̆ın incelendiği bu araştırmadan elde edilen sonuçlara göre; biçim boyutu dışında diğer tüm boyutlarda ve toplam puan açısından öğrencilerin yazılarının orta düzeyde okunaklı olduğu, en yüksek performansın satır takibi ve eğim boyutlarında en düşük performansın ise biçim boyutunda sergilendiği görülmüştür. Araştırmanın bu bulgusu, Ulu (2019) tarafından yapılan araştırmada elde edilen bulguyla örtüşmektedir. Ulu (2019) ilkokul 1. sınıf öğrencilerinin dik temel yazılarının okunakııık ve yazım hataları açısından incelediği çalışmasında öğrenci yazılarını boşluk, ebat, biçim ve satır takibi boyutlarında orta düzeyde okunaklı bulmuştur. Ayrıca bu bulgu, Babayiğit (2018)'in ilkokul 1. sınıf öğrencilerinin dik temel yazı ile harf yazım hatalarını incelediği araştırmasının sonuçlarıyla örtüşmektedir. Babayiğit (2018)'in araştırmasında öğrencilerin harfleri farklı şekillerde yazdıklarının belirtilmesi, yuvarlak harflerde yuvarlağın tam kapatılmaması gibi biçimsel hatalar olduğu örnekleri bu araştırmanın bulgularını desteklerken satır takibi boyutunda öğrencilerin uygun yazmadığı bulgusu, bu araştırmadan farklı sonuçlar ortaya koymaktadır. M. Doğan ve Z. Doğan (2018) birinci sınıf öğrencilerinin dik temel yazılarındaki hatalarını inceledikleri araştırmasında harflerin yazım yönü ve temel şekilleriyle ilgili hatalar tespit etmişlerdir. Bu bağlamda ilkokul 1. sınıf öğrencilerinin dik temel yazılarının okunaklı olduğu ancak biçim açısından harfleri tam olarak doğru biçimde yazamadıkları ortaya çıkmıştır.

Araştırmada ilkokul 1. sınıf öğrencilerinin dik temel yazılarının okunaklıık boyutundan aldıkları puanların boşluk, ebat ve biçim alt boyutlarında ve ölçeğin tamamında cinsiyete göre anlamlı farklıık gösterdiği ve ortaya çıkan bu farkın kız öğrenciler lehine olduğu anlaşıımaktadır. Bu durum Demiroğlu Memiş (2018)'in araştırmasında yazma eğiliminin ve Duncan (1982)'nin araştırmasında yazıda okunaklılığın kızlarda erkeklere oranla daha yüksek olduğu bulgusuyla örtüşmektedir. Demiroğlu Memiş (2018) araştırmasının önemli bir bulgusu da yazma eğilimi artıkça okunaklılığın da arttığıdır. Bu durum kız öğrencilerin yazma eğilimiyle ilişkili olarak daha okunakı yazdıkları şeklinde yorumlanabilir.

İlkokul 1. sınıf öğrencilerinin dik temel yazılarının okunaklılık boyutundan aldıkları puanların sosyo-ekonomik düzeye göre anlamlı farklılık göstermediği fakat sıra ortalamaları açısından üst sosyoekonomik düzeydeki öğrencilerin puanlarının alttakilere göre daha yüksek olduğu anlaşılmaktadır. Bu bulgu Kuşdemir, Katrancı ve Arslan (2018a)'in araştırmasında yer alan öğrencilerin yakın mesafeden bakarak yazdıkları yazıların okunaklılığının üst sosyo-ekonomik grup lehine anlamlı düzeyde farklılık gösterdiği bulgusuyla örtüşmektedir.

Öğrencilerin dik temel yazılarının okunaklılık boyutundan aldıkları puanlar Türkçe dersi akademik başarı düzeyine göre anlamlı farklılık gösterdiği ve başarılı öğrenciler lehine olduğu anlaşıımaktadır. Ayrıca başarılı ve başarısız öğrencilerin ölçekten aldıkları toplam puanlarında oldukça büyük bir fark bulunmaktadır. Ilgili alan yazın taraması sonucunda Türkçe dersi akademik başarısıyla yazı okunaklılığı arasında ilişkiyi inceleyen bir araştırmaya rastlanmamıştır. Fakat Yıldız (2019) çalışmasında yazma görevleri zorlaştıkça öğrencilerin dik temel yazıyı kullandıkları bulgusu yazma görevinin zorluğuyla akademik başarı arasındaki ilişkiyi düşündürmektedir. Araştırmada elde edilen bu bulguya karşın Kuşdemir, Katrancı ve Arslan (2018a)'in çalışmasında sınıf seviyesi arttıkça yazıların daha okunaksız olduğu belirlenmiştir.

Araştırmanın son alt problemi ilkokul 1. Sınıf öğrencilerinin "Çok Boyutlu Okunaklılık Ölçeği" den aldıkları puanların defter türüne göre anlamlı farklılık göstermediği görülmekle birlikte, sıra ortalamaları dikkate alındığında üç satır aralıklı defter kullanan öğrencilerin puan ortalamalarının klasik defter kullanan öğrencilerden daha yüksek olduğu anlaşılmaktadır. Nitekim 2005 yılından bu yana Türkçe Programlarında $(2005,259 ; 2009,238 ; 2015,11 ; 2018,12-13 ; 2019,12)$ okuma yazma 
öğretimi süreci boyunca dört çizgi üç aralıktan oluşan standart yazı defteri kullanılması gerektiği yer almaktadır. Bu nedenle öğretmenlerin kişisel tercihlerinden kaynaklı olarak yazı defteri kullanımından vazgeçip programa uygun davranması gerektiği şeklinde bir yorum yapılabilir.

Araştırmadan elde edilen sonuçlar doğrultusunda aşağıdaki önerilerde bulunulabilir;

* Dik temel yazıda okunaklılı̆ı etkileyen öğretimsel faktörler üzerine araştırmalar yapılabilir.

* Farklı sınıf seviyelerinde dik yazının gelişimi incelenebilir.

* Akademik başarı ve yazma arasındaki ilişkileri betimleyecek araştırmalar yapılabilir.

* ilkokul öğrencilerinin yazı okunaklılığını geliştirmeye yönelik programlar tasarlanabilir.

\section{Kaynaklar}

Arcagök, S., Kobak, G., Demir, M.K. ve Çavuş, Ş. (2017). Dik temel yazı ve bitişik eğik yazı kullanımına yönelik sınıf öğretmeni adaylarının görüşleri. Ana Dili Eğitimi Dergisi, 5(4), 861-879.

Asher, A.V. (2006). Handwriting instruction in elementary schools. American Journal of Occupational Therapy, 60, 461-471.

Atasoy, A. (2018). İlk yazma öğretimi: temel ve bitişik el yazısı. İçinde ilk okuma yazma ve Türkçe öğretimi. Bilginer Onan ve Mustafa Onur Kan (Eds). Nobel Yayıncllık. Ankara.

Bara, F. ve Morin, M.F. (2013). Does the handwriting style learned in first grade determine the sytle learned in first grade determine the sytle used in the fourth and fifth grades and influence handwriting speed and quality? A comparison between French and Quebec children. Psychology in the Schools, 50(6), 601-617.

Babayiğit, Ö. (2018). İlkokul birinci sınıf öğrencilerinin dik temel harf yazım hatlarının incelenmesi. Adıyaman Üniversitesi Eğitim Bilimleri Dergisi, 8(2), 176-199.

Babayiğit, Ö., Karabay, H.F., Metin, Z. ve Halıcı, B. (2018). Illkokul birinci sınıfta dik temel harflerle yazma öğretiminin incelenmesi. Uluslararası Türk Eğitim Bilimleri Dergisi [UTEB], 6(11), 45- 61.

Blair, L. A. (1957). An analysis of the trends of manuscript writing in the elementary schools. Unpublished master thesis. University of Southern California. USA.

Bulut, P., Kuşdemir, Y. ve Şahin, D. (2016). İlkokul ve ortaokulda yazı tercihi: öğrenci ve öğretmenler hangi yazı türünü kullanıyor? Mustafa Kemal Üniversitesi Sosyal Bilimler Enstitüsü Dergisi, 13(34), 98- 115.

Çakır, O., Aslantaş Arslan, G. ve Doğan, C.M. (2018) ilkokul öğretmenlerinin bitişik eğik yazı ve dik temel harflerin kullanımına ilişkin görüşlerinin değerlendirilmesi. Kastamonu Education Journal, 26(5), 1539-1550.

Demiroğlu Memiş, A.( 2018). Examination of legibility and writing speeds of primary school students with respect to writing disposition and writing style. Universal Journal od Educational Research, 6(5), 1050-1059.

Doğan, M. F. ve Doğan, Z. (2018). Identifiying common errors in vertical lowercase manuscript writing of the first graders in primary school. Jounal of Education and e- Learning Research, 5(3), 144156.

Duncan, S. (1982). Transition from manuscript writing to cursive writing at grade three. (Yayımlanmamış yüksek lisans tezi). Eastern Oregon State College. ABD.

Duran, E. (2009). Bitişik eğik yazı öğretimi çalışmalarının çeşitli değişkenler açısından incelenmesi. (Yayımlanmamış doktora tezi). Gazi Üniversitesi, Eğitim Bilimleri Enstitüsü. Ankara.

Duran, E. ve Akyol, H. (2010) Bitişik eğik yazı öğretimi çalışmalarının çeşitli değişkenler açısından incelenmesi. Türk Eğitim Bilimleri Dergisi, 8 (4) , 817-838.

Duran, E. (2011). Bitişik eğik yazı harflerinin yazım şekillerine ilişkin öğretmen görüşleri. On Dokuz Mayıs Üniversitesi Eğitim Fakültesi Dergisi, 30 (2) , 55-69.

Eagon, J. R. (1959). Evaluation of the importance of teaching manuscript writing in fourth, fifth and sixth grades. (Yayımlanmamış yüksek lisans tezi). The University of Southern California. ABD.

Erdoğan, T. (2012). Illköğretim birinci sınıf öğrencilerinin bitişik eğik yazma gelişimlerinin incelenmesi. Eğitim ve Bilim, 37(165), 93-103. 
Feder, K. P. ve Majnemer, A. (2003). Children's handwriting evaluation tools and their psychometric properties. Pysical \& Occupational Theraphy in Pediatrics, 23(3), 65-84.

Feder, K. P. ve Mejnemer, A. (2007). Handwriting development, competency, and intervention. Developmental Medicine \& Child Neurology, 49, 312-317.

Field, A. P. (2005). Discovering statistics using SPSS (Third edition). London: Sage Publishing.

Fraenkel, J. R., Wallen, N. E., \& Hyun, H. H. (2012). How to design and evaluate research in education (Eight edition). New York: McGraw-Hill.

Graham, S. ve Miller, L. (1980). Handwriting research and practice: a unified approach. Focus on Exceptional Children, 13(2), 1- 16.

Graham, S., Harris, R. K., Mason, L., Fink- Chorzempa, B., Moran, S. ve Saddler, B. (2008). How do primary grade teachers teach handwriting? A national survey. Read Write, 21, 49-69.

Güneş, F. (2017). Bitişik eğik ve dik temel yazı savaşları. Sınırsız Eğitim ve Araştırma Dergisi, 2(3), 1-20.

Kodan, H. (2016). Yazma güçlüğü olan üçüncü sınıf öğrencisinin el yazısı okunaklılığının geliştirilmesi: Eylem araştırması. Türkiye Sosyal Araştırmalar Dergisi, 2, 523-539.

Kuşdemir, Y., Katrancı, M. ve Arslan, F. (2018a). İlkokul öğrencilerinin yazı okunaklılığının incelenmesi. International Online Journal of Educational Sciences, 10 (3), 113- 129.

Kuşdemir, Y., Katrancı, M. ve Arslan, F. (2018b). Veli ve öğretmen gözüyle ilkokul öğrencilerinde yazı okunaklılı̆ı. Ana Dili Eğitimi Dergisi, 6(2), 455-476.

Kuru, O. (2014). Sınıf öğretmenliği 3. sınıf öğrencilerinin bitişik eğik yazılarının okunaklılık düzeylerinin belirlenmesi ve bitişik eğik yazıya ilişkin düşünceleri. Erzincan Üniversitesi Eğitim Fakültesi Dergisi, 16(1), 39-56.

Landis, J. ve Koch, G. (1977). The measurement of observer agreement for categorical data. Biomertrics, 33, 159-174.

Lessard, J-C. (1977). Du script à la cursive : L'écriture évolutive apporte à la didactique de l'écriture ce qui lui manquait depuis l'introduction du script, Québec français 28 (1977): 26-28.

McIntyre, K.A. (1974). Motivating early primary grade children to learn computation, reading, and manuscript writing utilizing music as catalyst. (Yayımlanmamış doktora tezi). University of Massachusetts. ABD.

Preston, L. E. (1941). A comparison of manuscript and cursive writing in the first grade.(Yayımlanmamış yüksek lisans tezi). University of Southern California. ABD.

Thomas, L.S. (1966). The effect of the time of change - over from manuscript to cursive writing on handwriting speed and legibility. (Yayımlanmamış yüksek lisans tezi). University of Montana. ABD.

Türkçe Öğretim Programı [1-8. Sınıflar].(2019) TC. Milli Eğitim Bakanlığı. Ankara.

Türkçe Öğretim Programı [1-8. Sınıflar].(2018) TC. Milli Eğitim Bakanlığı. Ankara.

Türkçe Öğretim Programı [1-8. Sınıflar].(2015) TC. Milli Eğitim Bakanlığı. Ankara.

Türkçe Öğretim Programı [1-8. Sınıflar].(2009) TC. Milli Eğitim Bakanlığı. Devlet Kitapları Müdürlüğü Basım Evi. Ankara.

Türkçe Öğretim Programı [1-8. Sınıflar].(2005) TC. Milli Eğitim Bakanlığı. Devlet Kitapları Müdürlüğü Basım Evi. Ankara.

Ulu, H. (2019). Illkokul birinci sınıf öğrencilerinin dik temel yazılarının okunaklılık ve yazım hataları açısından incelenmesi. International Journal of Field Education [IJOFE], 5(2), 195-211.

Yıldız, M. (2013). Yazma güçlüğü (disgrafi) olan bir ilkokul 2. Sınıf öğrencisinin el yazısı okunaklılığının geliştirilmesi: Eylem araştırması. Uşak Üniversitesi Sosyal Bilimler Dergisi, 16, 281-310.

Yıldız, M. (2019). Türkiye'de bitişik eğik yazı reformu ve sonrası: ilköğretim öğrencileri (4-8. Sınıf) hangi el yazısı stiliyle yazıyor? Eğitim ve Bilim, 44(197), 209-222.

Yıldız, M. ve Ateş, S. (2007). İlköğretim 3. sınıf öğrenci yazılarının okunaklılık bakımından incelenmesi. I. Ulusal Illköğretim Kongresinde sunulan poster bildiri. Hacettepe Üniversitesi. Ankara.

Yıldız, M. ve Ateş, S. (2010). İlkokuma yazmayı farklı yöntemlerle öğrenen ilköğretim 3. sınıf öğrencilerinin yazılarının okunakııık ve yazım hataları bakımından karşılaştııılması. TSA, 14(1), 11-30. 
Yıldız, M., Yıldırım, K. ve Ateş, S. (2009). Sınıf öğretmenlerinin sınıf tahtasına yazdıkları yazıların okunaklılık bakımından öğrencilere model olmadaki uygunluğu. Uluslararası insan Bilimleri Dergisi, 8(2), 75-88.

\section{Introduction}

\section{Extended Abstract}

The most important element in teaching writing is legibility. Legibility in handwriting is an eye's travel on handwriting without a pause due to formal reasons (Atasoy, 2018, 220). An examination of studies concerning legibility conducted in Turkey demonstrates that they generally analyse such elements as slope, space, size, form and keeping to the line (Yıldız, Yıldırım and Ateş, 2009; Kuru, 2014; Yıldız, 2013; Kodan, 2016). On examining international studies, it is apparent that studies on teaching manuscript writing dates back to old times. Findings demonstrate that teachers of first graders regard teaching basic manuscript writing to starter level students as easy and they think it is more appropriate in terms of teaching reading and that they think students who write legible manuscript writing will also write legible cursive writing (Preston, 1941; Blair, 1957; Thomas, 1966; Mclntyre, 1974; Duncan, 1982). Following the re-start of teaching manuscript writing move in Turkey, studies investigating students' handwriting in fact demonstrated that manuscript writing did not cause a change in legibility on contrary to the highly-debated on-going discussion (Babayiğit, 2018; Babayiğit, Karabay, Metin and Halıcı, 2018; Ulu, 2019). In this context, this present study is significant in that it analyses legibility in manuscript writing and that it takes into account factors such as gender, success and socioeconomic status which affect legibility.

This paper aims to analyse the legibility of the first graders' manuscript writing. In accordance with its purpose, this study examines the level of legibility of the first graders' handwriting and investigates whether or not the scores the students receive from the sub-factors of legibility and their total scores differ significantly according to gender, socioeconomic status, academic achievement levels and he note books they use.

\section{Method}

This study aims to analyse the first graders' manuscript writing in terms of legibility. It was designed upon survey model. Participants were composed of 136 primary school students who were the first graders in a state school located in Ankara city centre. The students were included in the study because they were convenient and voluntary, those who did completed the literacy process were not included in the study. The research was conducted in 2019-2020 academic year in the context of first grade Turkish course. "Multi-Dimensional Legibility Scale" developed by Yıldız and Ateş (2007) was adapted and used in analysing students' manuscript writing. Thus, students' writing in their notebooks by using manuscript writing was evaluated according to the criteria available in the scale. The evaluations were made according to the criteria in the scale by two researchers who were the experts in the domain. Cohen's Kappa was administered on the data to determine the interrater agreement between the evaluation results and to check whether they were reliable. The result showed that there was considerable agreement between the raters. The criteria set for legibility in the scale were slope, space, size, form and keeping to the line. Non-parametric statistics were used in analysing the data since the data obtained from the sub-factors of the "MultiDimensional Legibility Scale" did not display normal distribution and since the variance was not homogeneous. Mann-Whitney $U$ test was applied to determine whether the scores coming from two unrelated samples differed significantly.

\section{Result and Discussion}

The results obtained in this paper which investigated the legibility of the first graders' manuscript writing demonstrated that students' scripts had medium legibility in all other sub-factors except form and size, and in total scores that the highest performance was in keeping to the line and in slope but that the lowest performance was in form. Findings were similar to Ulu (2019)'s research 
results. Ulu (2019) found out that students' handwriting had medium level of legibility in terms of space, size, form and keeping to the line. This result displayed similarity with Babayiğit (2018)'s findings which investigated the first graders' errors in forming the letters in manuscript writing. The claims of Babayiğit (2018) that students made formal errors such as writing letters in different forms and they did not complete the round shape in round letters supported the findings obtained in this study whereas the finding that students did not write appropriately in terms of keeping to the line obtained in Babayiğit (2018) demonstrated different results than the present stuy. In a study analysing the first graders' manuscript writing, M. Doğan and Z. Doğan (2018) detected errors in writing letters and in relation to the basic shapes of the letters. The researchers found that the students' manuscript writing was legible but the letters were not written correctly in terms of form.

It was found that the scores students received in legibility differed significantly according to gender in the sub-scales of space, size and form as well as in the overall scale and that the difference was in favour of girls. It was similar to the one obtained in Demiroğlu and Memiş (2018) who concluded that writing inclination was higher in girls and also similar to Duncan (1982)'s research which revealed that girls' handwriting was more legible than boys'. It can be interpreted as that girls write more legibly due to their inclination to write.

It became apparent that first graders' scores in legibility of manuscript writing did not differ significantly according to socioeconomic status. However, it was also apparent that the scores received by students with higher socioeconomic status in terms of mean rank were higher than those with lower socioeconomic status. It displayed similarity to the findings obtained by Kuşdemir, Katrancı and Arslan (2018a) arguing that the legibility of handwriting produced by looking from a close distance differed significantly in favour of groups with higher socioeconomic status.

It was found in this study that the scores which students received from the legibility of their manuscript writing differed significantly in terms of Turkish lesson academic achievement levels and that the differences were in favour of students who were successful. Additionally, great differences were detected between the total scores that successful and unsuccessful students received from the scale. No research investigating the correlations between Turkish lesson academic achievement and the legibility of handwriting were found upon literature review. However, the finding obtained in Yıldız (2019) that students use manuscript writing more and more as the task of writing becomes more difficult makes us think of the correlations between the difficulty of writing task and academic achievement.

Finally, this study found out that the first graders' manuscript writing scores did not differ significantly according to the types of notebooks they used for writing, but that the students who used notebooks with three line spacing had higher score averages than those who used traditional notebooks. Indeed, the Turkish course curricula which have been used since 2005 (2005, 259; 2009, $238 ; 2015,11 ; 2018,12-13 ; 2019,12)$ demand that standard notebook with four lines and three lines spacing be used for handwriting. Therefore, behaviour consistent with the demands of the curriculum should be displayed instead of teachers' personal choice. Thus, the following recommendations could be made in accordance with the results obtained:

* Instructional factors influencing legibility in manuscript writing could be investigated.

* The development of non-italic handwriting could be examined at different grade levels.

* Research describing the correlations between academic achievement and writing could be implemented.

* Programmes intending to improve the legibility of primary school students' handwriting could be designed. 
Ekler

Ek 1. Çok Boyutlu Okunaklılık Ölçeği (Yıldız ve Ateş, 2007, 2010)

\begin{tabular}{|c|c|c|c|}
\hline \multicolumn{4}{|c|}{ Çok Boyutlu Okunaklılık Ölçeği } \\
\hline Okunaklılık Kriterleri & $\begin{array}{l}\text { Tamamen Yeterli } \\
\text { (3) }\end{array}$ & $\begin{array}{l}\text { Orta Düzeyde Yeterli } \\
\text { (2) }\end{array}$ & $\begin{array}{l}\text { Hiç Yeterli Değil } \\
\text { (1) }\end{array}$ \\
\hline EĞì & $\begin{array}{l}\text { Harfler } 90 \text { derecelik bir } \\
\text { eğimle metin boyunca } \\
\text { düzgün ve tam olarak } \\
\text { yazılmış. } \\
\text { ( ) }\end{array}$ & $\begin{array}{l}\text { Harfler tam ölçülere } \\
\text { uygun olmasa da yazı } \\
\text { sağa ya da sola eğimli } \\
\text { olarak yazılmış ve bu } \\
\text { yatkınlık metin } \\
\text { boyunca kısmen devam } \\
\text { ediyor. } \\
\text { ( ) }\end{array}$ & $\begin{array}{l}\text { Harfler } \\
\text { düzensiz. Yazıda hem } \\
\text { sağa hem sola eğim / } \\
\text { yatıklık } \\
\text { görülmekte. } \\
\text { ( ) }\end{array}$ \\
\hline BOŞLUK & $\begin{array}{l}\text { Harfler, kelimler ve } \\
\text { cümleler arasındaki } \\
\text { boşluk uygun ve tutarlı } \\
\text { biçimde metin boyunca } \\
\text { devam ediyor. } \\
\text { ( ) }\end{array}$ & $\begin{array}{lr}\text { Harfler, kelimeler ve } \\
\text { cümleler } & \text { arasındaki } \\
\text { boşluklarda } & \text { bazı } \\
\text { tutarsızlıklar } & \text { var. } \\
\text { Boşluklar } & \text { metnin } \\
\text { tamamında } & \text { tutarlı } \\
\text { değil. } & (\mathrm{l}) \\
\end{array}$ & $\begin{array}{l}\text { Harfler, kelimler ve } \\
\text { cümleler arasındaki } \\
\text { boşluklar metnin } \\
\text { tamamında tutarsız ve } \\
\text { yeterli değil. } \\
\text { ( ) }\end{array}$ \\
\hline EBAT & 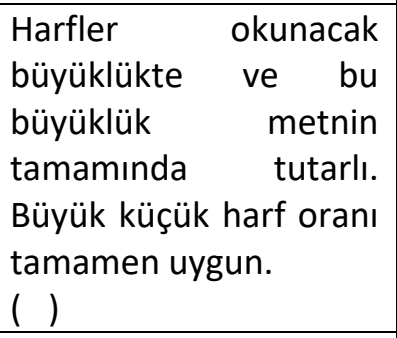 & $\begin{array}{l}\text { Harflerin ebatları } \\
\text { normalden büyük ya da } \\
\text { küçük olmasına rağmen } \\
\text { tutarlı. Büyük küçük } \\
\text { harf oranlarında da } \\
\text { dengesizlikler var. } \\
\text { ( ) }\end{array}$ & $\begin{array}{l}\text { Harflerin büyüklükleri } \\
\text { okunmayacak durumda } \\
\text { ve düzensiz. Büyük } \\
\text { küçük harf oranları da } \\
\text { dengesiz ve tutarsız. } \\
\text { ( ) }\end{array}$ \\
\hline віс̧ім & $\begin{array}{l}\text { Harfler kurallarına tam } \\
\text { uygun olarak yazılmış. } \\
\text { Başlama ve bitiş yerleri } \\
\text { uygun ve doğru şekilde } \\
\text { yapılmıs. Alt ve üst } \\
\text { uzantılar orantılı. } \\
\text { ( ) }\end{array}$ & $\begin{array}{l}\text { Harflerin başlama ve } \\
\text { bitiş yerlerinde, alt ve } \\
\text { üst uzantılarının } \\
\text { oranlarında bazı } \\
\text { eksiklikler var. } \\
\text { ( ) }\end{array}$ & $\begin{array}{l}\text { Harflerin yazılışları } \\
\text { kuralsız olduğu gibi alt } \\
\text { ve üst uzantılarla } \\
\text { başlama ve bitiş yerleri } \\
\text { yetersiz. } \\
\text { ( ) }\end{array}$ \\
\hline SATIR TAKIBI & $\begin{array}{l}\text { Satır oldukça düzgün } \\
\text { takip edilmiş. Satırdan } \\
\text { üste çıkma ve alta } \\
\text { kayma yok. Satır } \\
\text { sonunda boşluklar } \\
\text { tutarlı ve taşma yok. } \\
\text { ( ) }\end{array}$ & $\begin{array}{l}\text { Satır takibinde bazen } \\
\text { alta kayma ve üste } \\
\text { çıkmalar var. Satır sonu } \\
\text { taşmaları ve boşluk } \\
\text { düzensizlikleri az da } \\
\text { olsa görülüyor. } \\
\text { ( ) }\end{array}$ & $\begin{array}{lr}\text { Satır takibi oldukça } & \text { yetersiz. Alta kayma ya } \\
\text { da üste çıkmalar sürekli } \\
\text { var. Satır sonu } \\
\text { taşmaları ve boşluk } \\
\text { düzensizlikleri } \\
\text { fazla. } \\
\text { ( ) }\end{array}$ \\
\hline
\end{tabular}

